\title{
Influence of Rising of a River Water Level on Groundwater Flow and Stability of a Landslide
}

\author{
Yinger Deng ${ }^{1, a}$, Jing $\mathrm{Yu}^{1, b}$, Shangjun $\mathrm{Cai}^{1, \mathrm{c}}$ and Xin Peng ${ }^{1, \mathrm{~d}}$ \\ ${ }^{1}$ State Key Laboratory of Geohazard Prevention and Geoenvironment Protection, Chengdu \\ University of Technology, Chengdu 610059, China; \\ a546730457@qq.com, b1225965177@@qq.com, caishangjun@cdut.cn, d2250656391@qq.com
}

Keywords: stability of a landslide, groudwater flow, weak permeable media, rising of a river water level, changes of conditions

Abstract. This paper took certain a landslide in Sichuan province as a research object and focused on characteristics of groundwater flow and stability of the landslide with changes of conditions. Three-dimensional conceptual model was established for groundwater flow in the landslide with weak permeable media. Results show that there is good agreement between numerical calculation and observed groundwater table and that relative error of groundwater table calculated from the model is less than $0.13 \%$. During the rising of the river water level, groundwater table in the slope body increases gradually and the landslide stability coefficient changes from rising, then declining to rising. The minimum stability coefficient of the landslide is $3 \%$ lower than that of the natural condition. The results can provide stability evaluation and engineering prevention treatment of the landslide with scientific basis.

\section{Introduction}

Groundwater can flow in different kinds of porous rock and soil media [1, 2]. It involves geological engineering and geotechnical engineering. Several researchers have investigated problems on groundwater flow and stability of the landslide such as Mao [3] and Zheng et al. [4]. Mao et al. [3] reviewed development and current situation on methods of calculation and control of seepage. Zheng et al. [4] present methods of calculation of seepage forces and phreatic surface under draw down conditions. Chen and Cascini et al. $[5,6]$ researched effect of rainfall on slope stability in mountainous area.

In this paper, we take certain a landslide in Sichuan province as a research object and focused on groundwater flow and stability of the landslide. We will establish a three-dimensional conceptual model for groundwater flow in the landslide with weak permeable media. Moreover, we will calculate characteristics of groundwater table and stability of the landslide with the river water level rising. All the researches will provide stability evaluation and engineering treatment of the landslide with scientific basis.

\section{Conceptual Model for Groundwater Flow}

Certain a landslide with weak permeable media was selected. Range of the research area is shown in Fig. 1. The landslide is porous media with weak permeable media. The quaternary loose media are permeability media. Sliding zone soil is weak permeable media. Boundaries of the landslide are made up of impermeable boundary of the left and right sides, the constant head boundary of trailing edge and the variable head boundary of leading edge boundary.

\section{Mathematical Model of Groundwater Flow}

A partial differential equation for groundwater flow in the landslide is given by equation (1) provided that the coordinate axes are assumed oriented parallel to the principle axes of the landslide porous media. 


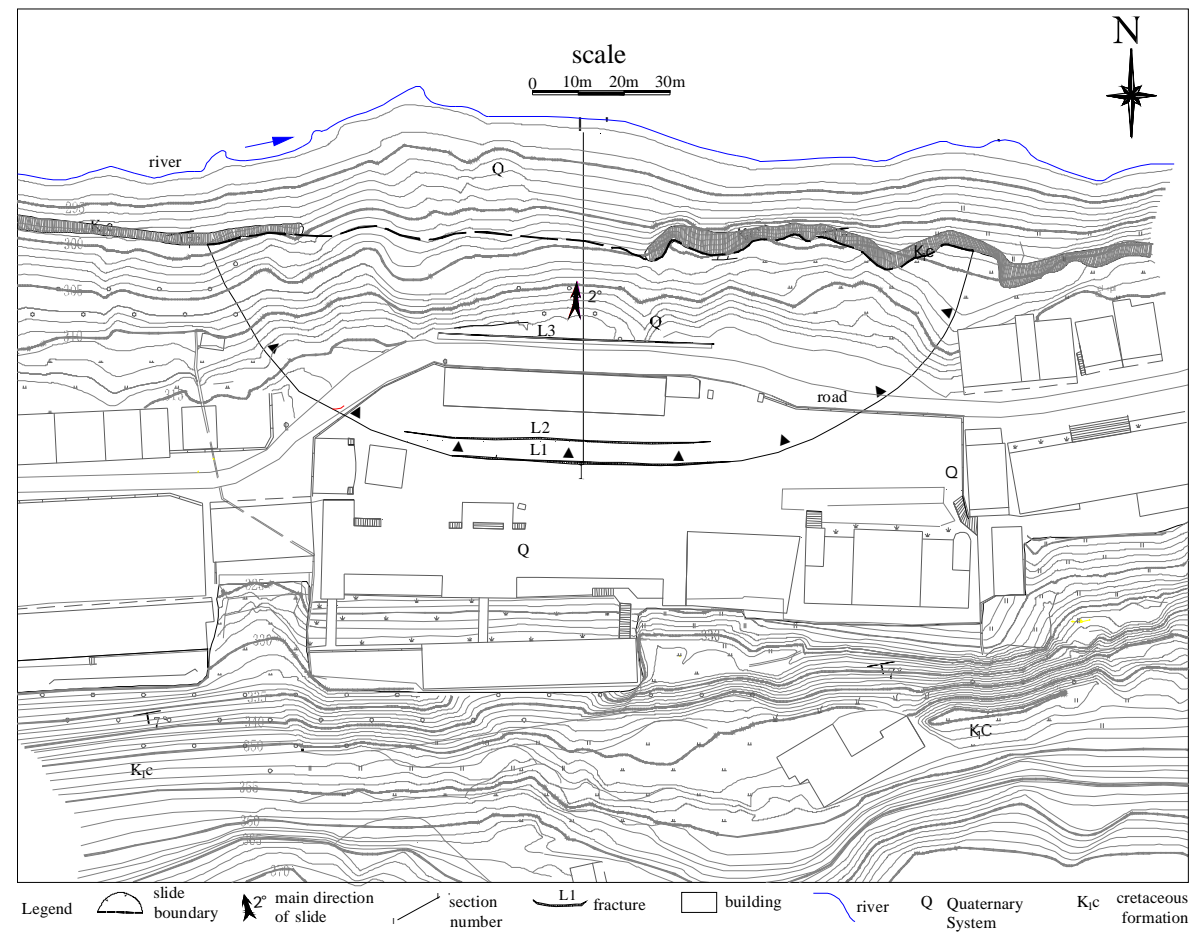

Fig. 1 Research area range (N: North)

$$
\sum_{i=1}^{3} \frac{\partial}{\partial x_{i}}\left(K_{i} \frac{\partial H}{\partial x_{i}}\right)+W=S_{s} \frac{\partial H}{\partial t}
$$

Where $H$ is head of groundwater in the landslide, $K_{i}$ is permeability coefficient of $x_{i}$ direction, $x_{i}(i=1$, $2,3)$ is component of a spatial position $\mathbf{x}, W$ is a source or sink, $S_{s}$ is specific storage, $t$ is time. Initial condition is

$$
\left.H\right|_{t=0}=H_{0}(\mathbf{x}), \mathbf{x} \in(R)
$$

Boundary conditions are

$$
\begin{aligned}
& \left.H\right|_{\Gamma_{1}}=\varphi_{1}(\mathbf{x}, t), \mathbf{x} \in\left(\Gamma_{1}\right), t \in(0, \tau) \\
& \left.K_{i} \frac{\partial H}{\partial x_{i}} n_{i}\right|_{\Gamma_{2}}=\varphi_{2}(\mathbf{x}, t), \mathbf{x} \in\left(\Gamma_{2}\right), t \in(0, \tau)
\end{aligned}
$$

where $H_{0}(\mathbf{x})$ is initial head of groundwater in the landslide, $\varphi_{1}(\mathbf{x}, t)$ is a known function on the boundary $\Gamma_{1}, \varphi_{2}(\mathbf{x}, t)$ is a known function on the boundary $\Gamma_{2}, \Gamma_{1}$ is the first kind boundary, $\Gamma_{2}$ is the second kind boundary, $n_{i}$ is component of a unit vector in the direction of the outer normal, $\tau$ is time span.

\section{Method of Calculating Stability Coefficient of a Landslide}

The stability coefficient is defined as

$$
F_{s}=\frac{\sum_{i=1}^{n-1}\left(\left(W_{i}\left(\left(1-r_{U}\right) \cos \alpha_{i}-A \sin \alpha_{i}\right) \tan \phi_{i}+C_{i} L_{i}\right) \prod_{j=i}^{n-1} \varphi_{j}\right)+R_{n}}{\sum_{i=1}^{n-1}\left(\left(W_{i}\left(\sin \alpha_{i}+A \cos \alpha_{i}\right)\right) \prod_{j=i}^{n-1} \varphi_{j}\right)+T_{n}}
$$


Here

$$
\begin{aligned}
& R_{n}=\left(W_{n}\left(\left(1-r_{U}\right) \cos \alpha_{n}-A \sin \alpha_{n}\right)\right) \tan \phi_{n}+C_{n} L_{n} \\
& T_{n}=W_{n}\left(\sin \alpha_{n}+A \cos \alpha_{n}\right. \\
& \prod_{j=i}^{n-1} \varphi_{j}=\varphi_{i} \varphi_{i+1} \varphi_{i+2} \cdots \cdots \cdots \varphi_{n-1}
\end{aligned}
$$

Here $\varphi_{j}$ can be defined as equation (9)

$$
\varphi_{j}=\cos \left(\alpha_{i}-\alpha_{i+1}\right)-\sin \left(\alpha_{i}-\alpha_{i+1}\right) \tan \phi_{i+1}
$$

where $W_{i}$ is weight of bar $i, C_{i}$ is cohesion of bar $i, L_{i}$ is length of sliding surface of bar $i, \phi_{i}$ is angle of internal friction of bar $i, \alpha_{i}$ is slip angle of bar $i, A$ is earthquake acceleration, $r_{U}$ is pore pressure ratio, $F_{s}$ is stability coefficient of a landslide.

\section{Basic Parameters}

The parameters are shown in the table 1 .

Table 1 Basic parameters of a model

\begin{tabular}{ccccccc}
\hline Formation & $\begin{array}{c}K_{x} \\
(\mathrm{~m} / \mathrm{d})\end{array}$ & $\begin{array}{c}K_{y} \\
(\mathrm{~m} / \mathrm{d})\end{array}$ & $\begin{array}{c}K_{z} \\
(\mathrm{~m} / \mathrm{d})\end{array}$ & $\begin{array}{l}\text { specific } \\
\text { yield }\end{array}$ & $\begin{array}{c}\text { effective } \\
\text { porosity }\end{array}$ & $\begin{array}{c}\text { storage } \\
\text { coefficient }\end{array}$ \\
\hline sliding body & 4.22 & 4.22 & 4.22 & 0.09 & 0.41 & 0.22 \\
sliding zone & 0.62 & 0.62 & 0.08 & 0.06 & 0.38 & 0.15 \\
residual slope soil & 1.61 & 1.61 & 1.61 & 0.06 & 0.39 & 0.12 \\
highly weathered & 0.086 & 0.086 & 0.02 & 0.05 & 0.26 & 0.06 \\
moderate weathered & 0.003 & 0.003 & 0.001 & 0.03 & 0.22 & 0.001 \\
\hline
\end{tabular}

\section{Results and Discussion}

Validation of the model was examined so that the model can be in agreement with hydrogeological conditions. Relative error of groundwater table calculated from the model is less than $0.13 \%$. There is good agreement between numerical calculation and observed results, as is shown in table 2.

Table 2 Difference between observed results and calculated results

\begin{tabular}{ccc}
\hline Well of serial number & Observed $(\mathrm{m})$ & Calculated $(\mathrm{m})$ \\
\hline 1 & 302.90 & 302.89 \\
2 & 306.30 & 306.44 \\
3 & 302.65 & 302.79 \\
4 & 304.38 & 304.77 \\
\hline
\end{tabular}

Fig. 2 shows calculated groundwater contour lines in the landslide. Fig. 3 shows changes of stability coefficient of the landslide with water level changing from $302 \mathrm{~m}$ to $316 \mathrm{~m}$ when river water level rises at a speed of $2.8 \mathrm{~m} / \mathrm{d}$. Groundwater table in the slope body increases gradually with the river water level increasing. The landslide changes from the slope surface to a deep place because of coefficient of permeability of the slope body. During the rising of the river water level, the landslide stability coefficient shows a trend from rise, then decline to rise. The minimum stability coefficient of the landslide is $3 \%$ lower than that of the natural condition. 


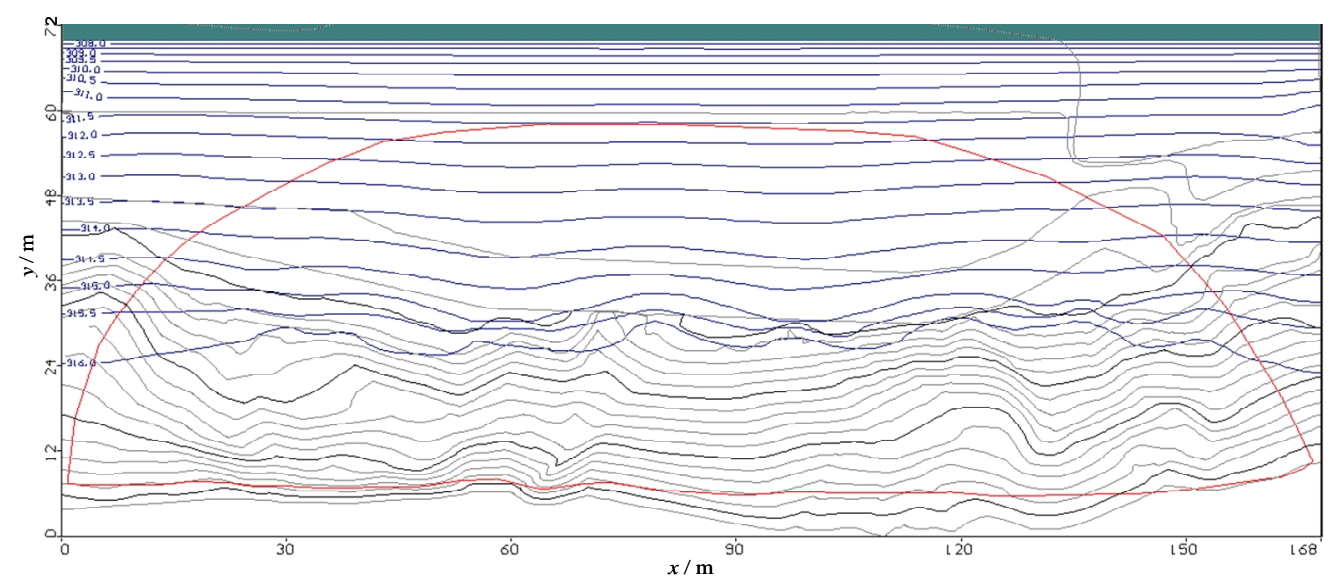

Fig. 2 Calculated groundwater table contour lines in the landslide

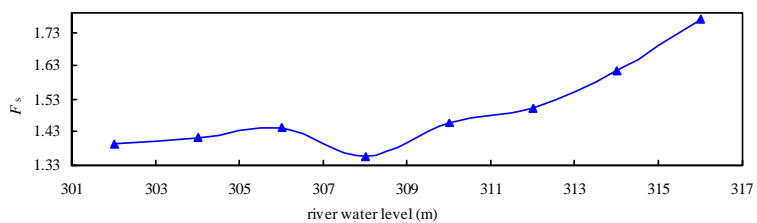

Fig. 3 Stability coefficient of the landslide changes with river water level

\section{Conclusions}

Three-dimensional conceptual model was established for groundwater flow in the landslide with weak permeable media. There is good agreement between numerical calculation and observed groundwater table. During the rising of the river water level, groundwater table in the slope body increases gradually and the landslide stability changes from rising, then declining to rising. The minimum stability coefficient of the landslide is $3 \%$ lower than that of the natural condition.

\section{Acknowledgements}

This work was supported by the National Natural Science Foundation of China (under Grant Nos. 41172277, 40202036, 40572163) and the Specialized Research Fund for the Doctoral Program of Higher Education of China (under Grant No. 20095122110006). The authors would like to thank Professors X. M. Fu, S. Y. Jia and X. J. Yu for their help.

\section{References}

[1] M. Bai, D. Elsworth, J.C. Roegiers: Water Resour Res Vol. 29 (1993), p.1621.

[2] S.P. Neuman, W.A. Illman, V.V. Vesselinov, D.L. Thompson, G. Chen, and A. Guzman: Conceptual Models of Flow and Transport in the Fractured Vadose Zone (National Academy Press, Washington, D.C. 2001).

[3] C.X. Mao: Calculation and control of seepage (Second edition). Beijing: China Water Conservancy and Hydropower press, 2003. (In Chinese)

[4] Y.R. Zheng, W.M. Shi, W.X. Kong: Chinese Journal of Rock Mechanics and Engineering, Vol.23 (2004), p.3203. (In Chinese)

[5] J. Chen, Z.F. Yang, X. LI: Chinese Journal of Rock Mechanics and Engineering, Vol.24 (2005), p.3052-3056. (In Chinese)

[6] L. Cascini, M. Calvello, G.M. Grimaldi: Journal of Geotechnical and Geoenvironmental Engineering, Vol.136 (2010), p.1220. 